\title{
Improvement of wind power units towers constructions and their numerical simulation
}

\author{
Linar Sabitov ${ }^{1,2 *}$, Levon Mailyan ${ }^{3}$, Leysan Akhtyamova ${ }^{3}$, Almaz Ziganshin ${ }^{1,3}$, and Serdar \\ Yazyev $^{3}$ \\ ${ }^{1}$ Kazan State Power Engineering University, 51 Krasnoselskaya str., Kazan, 420066, Russia \\ ${ }^{2}$ Kazan (Volga Region) Federal University, 18 Kremlevkaya str., Kazan, 420008, Russia \\ ${ }^{3}$ Don State Technical University, 1 Gagarin sq., Rostov-on-Don, 344002, Russia
}

\begin{abstract}
This article discusses new efficient tower structures (power transmission towers (PTT), support for wind turbines (WT) etc.), for which the patents for inventions of the Russian Federation have been obtained. Methods for their calculation in the ANSYS software package are given in order to determine the stress-strain state (SSS) and defining their actual work. Application of new technical solutions in the WTtowers construction will reduce material consumption by $15 \%$.
\end{abstract}

\section{Introduction}

During the tower structures'construction, three types of technical solutions are mainly used: a) lattice, b) solid-wall, b) combined [2] (Figure 1).

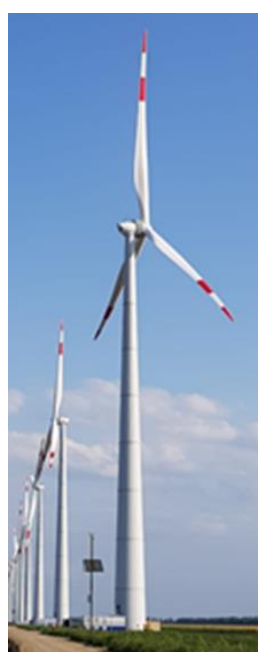

a)

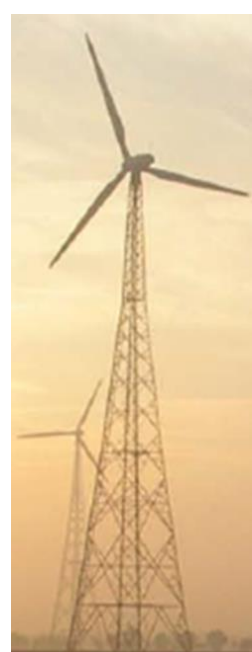

b)

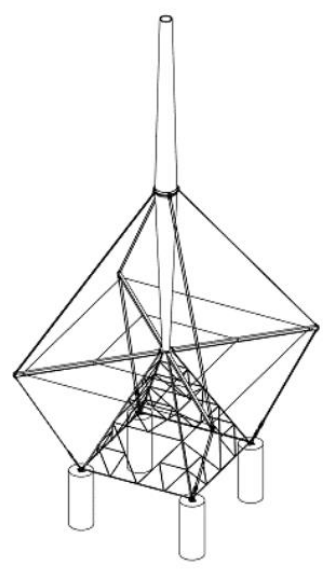

c)

Fig.1. Structures of wind turbines towers a) solid-wall; b) lattice; c) combined (hybrid).

\footnotetext{
*Corresponding author: sabitov-kgasu@mail.ru
} 
For each type of solutions there is an area of optimal application according to the minimum mass criterion [2]. In this article, we will consider the construction of a solid-wall tower with new technical solutions presented in Figure $1[3,4]$.

\section{Main part}

The researchobject is a real tower WTAcciona AW-82-1500 IEC IIIB classused in the construction of the Adyghe wind power station (WPS). A general view of the wind power plant is shown in Figure 2 a

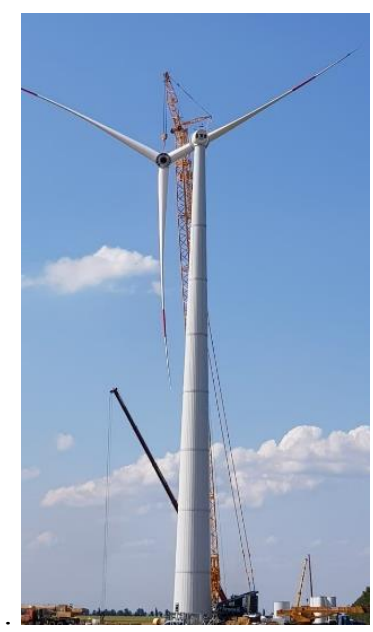

a)
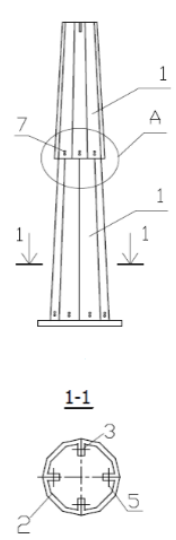

b)

)

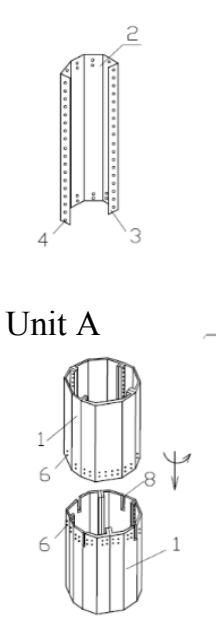

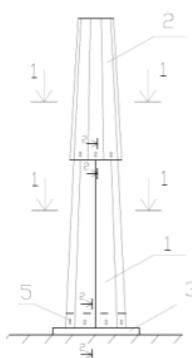

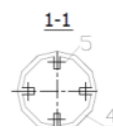

fig. 2

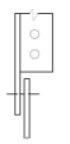

Fig. 2. The structure of the wind turbine tower: $a$ ) WT general view Acciona AW-82-1500 class IEC IIIB; $b$ ) new telescopic joint design (patent RF № 2743116); new base design (RF patent № 2743980)

WT characteristics are presented in Table 1.

Table 1. Characteristics of a wind power plant Acciona AW-82-1500 IEC IIIB classof the Adyghe wind power station

\begin{tabular}{|c|c|c|}
\hline no. & Name & Value \\
\hline 1 & Installed capacity, $\mathrm{MW}$ & 1.5 \\
\hline 2 & Swept area, $\mathrm{m}^{2}$ & 5345 \\
\hline 3 & Number of blades, $\mathrm{pc}$. & 3 \\
\hline 4 & Wind wheel diameter, $\mathrm{m}$ & 82 \\
\hline 5 & Length of one blade, $\mathrm{m}$ & 39 \\
\hline 6 & Weight of one blade, $\mathrm{kg}$ & 5780 \\
\hline 7 & Rotor weight, $\mathrm{kg}$ & 32340 \\
\hline 8 & Gondola weight, $\mathrm{kg}$ & 52500 \\
\hline 9 & Tower height to hub axis, $\mathrm{m}$ & 80 \\
\hline 10 & Hubradius, $\mathrm{m}$ & 3.3 \\
\hline
\end{tabular}

Tower - three-section thin-walled rod-shell; bottom section wall thickness $-\mathrm{t} \_1=30$ $\mathrm{mm}$, medium $-\mathrm{t} \_1=25 \mathrm{~mm}$ and top $-\mathrm{t} \_1=15 \mathrm{~mm}$, the tower has a cross-sectional diameter along the outer perimeter at the bottom $-D_{-} 1=4.3 \mathrm{~m}$, upstairs $-\mathrm{D}_{-} 2=2.6 \mathrm{~m}$. Material of construction - steel C355. To take into account physical nonlinearity, the Bilinear 
Kinematic Hardening model was used, shown in Figure 2. The yield surface is described by the Von Mises criterion and is a cylinder which axis coincides with the hydrostatic compression axis in the principal stress axes (Figure 3).

The design model is represented by a three-section bar finite element FE-410 variable stiffness. The wind wheel, rotor and nacelle are modeled as a concentrated mass at the towertop. The interface between the tower and the foundation is rigid. The calculation was carried out both for the main combination of loads and for a special one. According to the micro-seismic zoning report, the seismicity of the construction site is 8 points on the MSK64 scale. The seismic impact of the level "Maximum design earthquake" is presented by a one-component accelerogram (Figure 4).

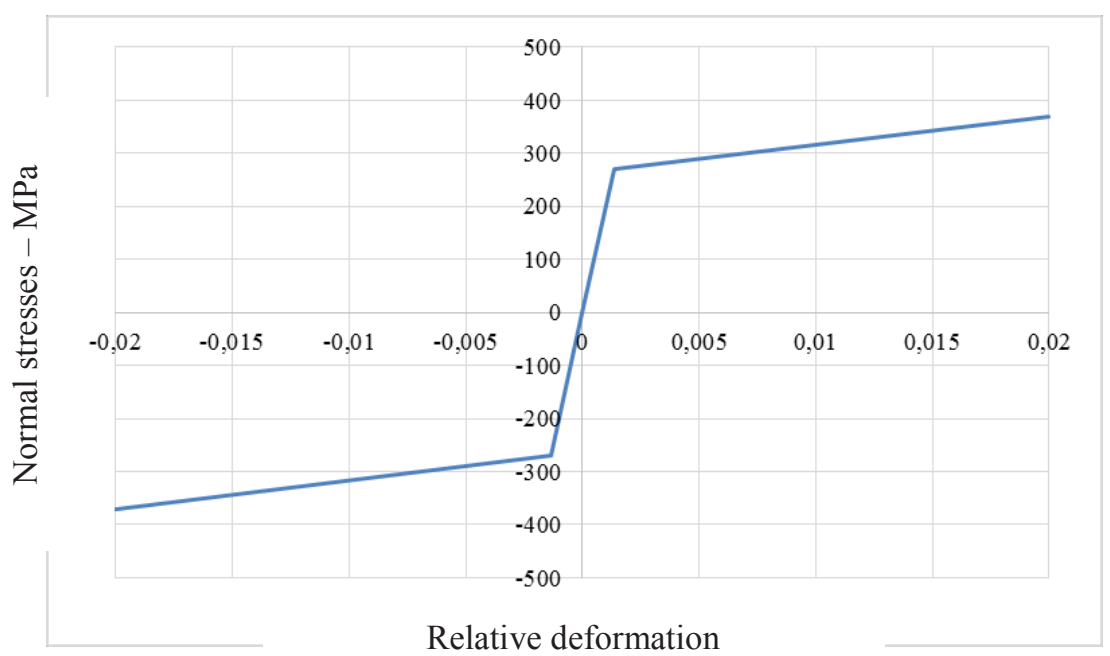

Fig. 3. Bilinear diagram of steel deformation

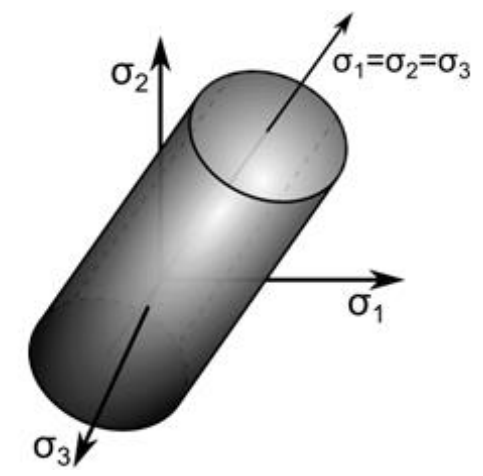

Fig. 4. Yield surface according to the Von Mises criterion in the axes of principal stresses 


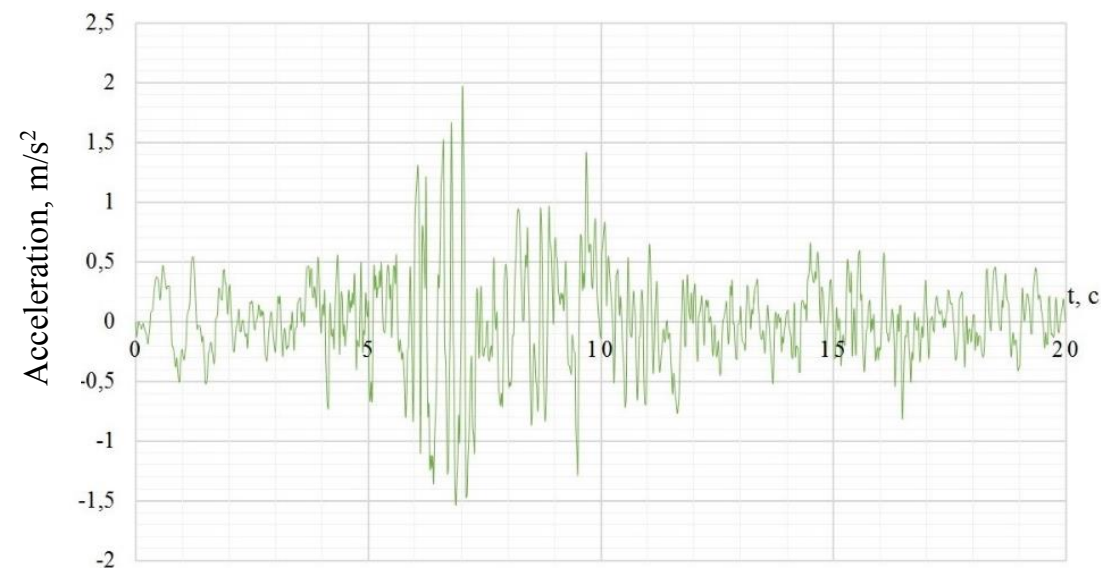

Fig. 5. One-component accelerogram of seismic impact

The spatial nature of the seismic impact was not taken into account in the calculation due to the use of a symmetrical section. The support node and the telescopic joint of the joint behind are modeled using lamellar finite elements FE-42, 44. Foundation bolts are modeled by single-node elastic constraint finite elements FE-56, a telescopic joint bolt using a universal bar finite element FE-10. The transfer of internal forces from the rod finite elements to the node model is carried out by absolutely rigid bodies. General view of the nodes are shown in Figures 6, 7.

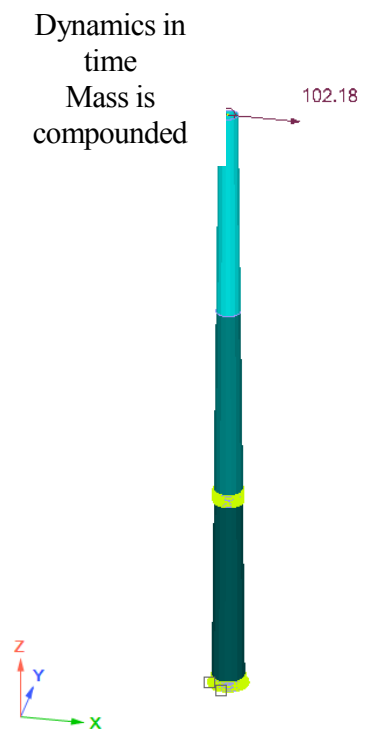

a)

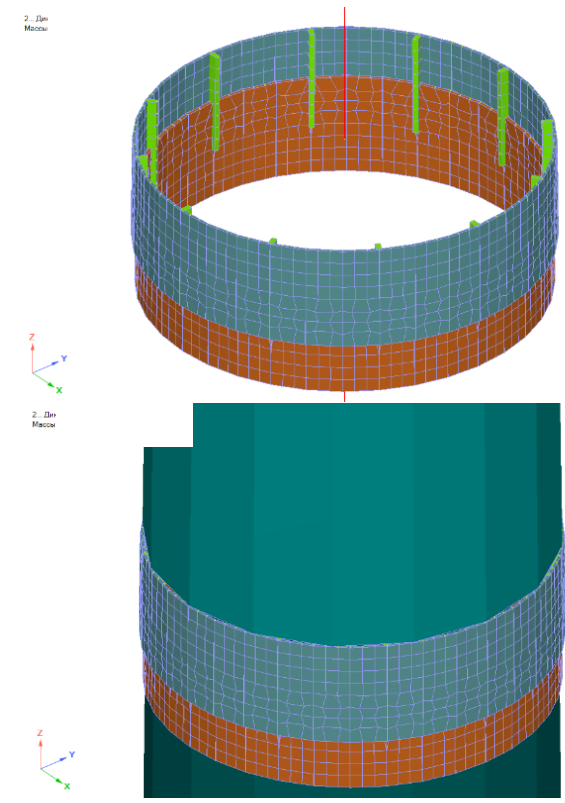

b)

Fig. 6. Design model of a wind power plant a) general view of the model; b) general view of the telescopic joint.

The general results of the calculation for the support node are shown in Figure 7. Additionally, Figure 8 shows the graphs of the internal forces in foundation bolts during the seismic action period. 


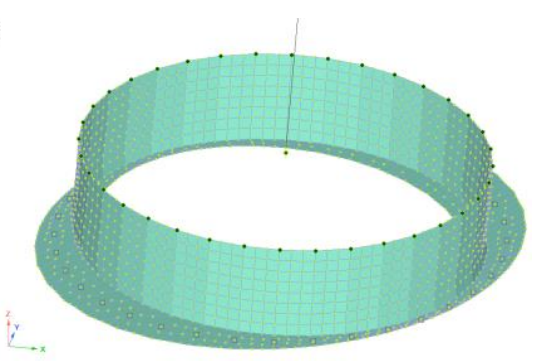

a)

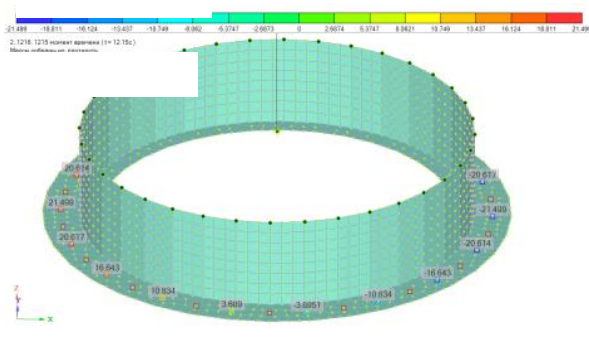

b)

Fig. 7. WT tower base: $a$ ) deformed view of the support unit; $b$ ) mosaic of longitudinal forces inFE-56, modeling foundation bolts

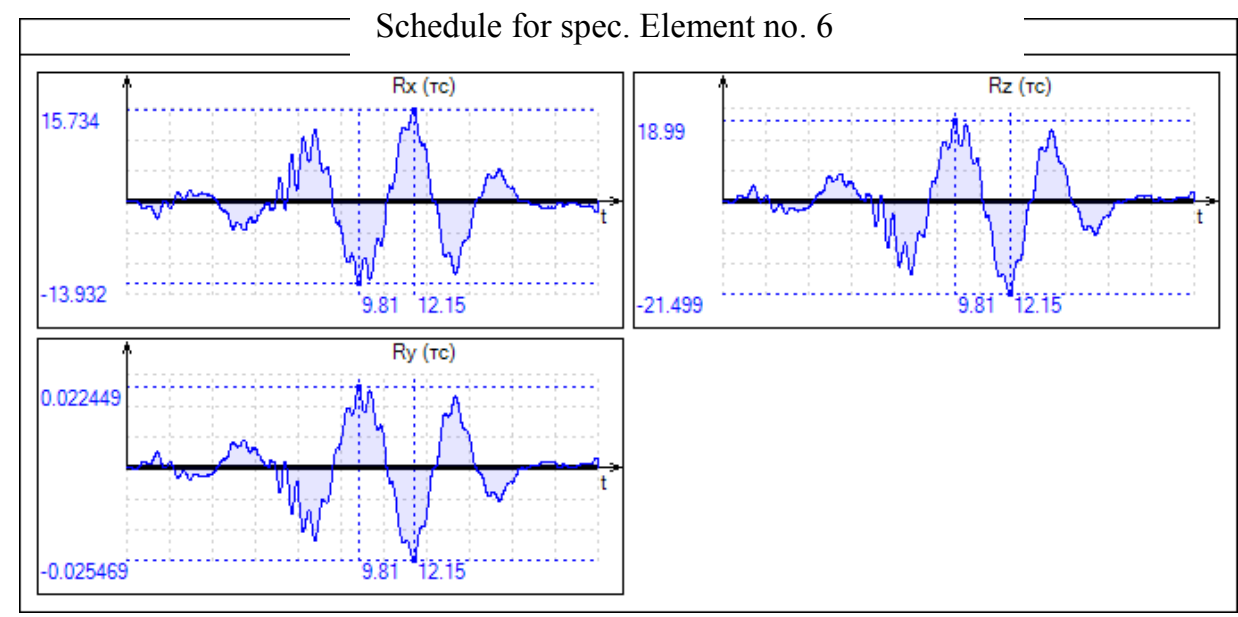

Fig. 8. Graphs of internal forces in foundation bolts during the seismic actionperiod.

To illustrate the results obtained, Figures 9-12 show the stress intensity distributions according to Von Mises for the calculationvariant from a special combination. The von Mises stress intensity is calculated by the formula:

$$
\sigma_{i}=\sqrt{\frac{1}{2}\left(\left(\sigma_{1}-\sigma_{2}\right)^{2}+\left(\sigma_{2}-\sigma_{3}\right)^{2}+\left(\sigma_{3}-\sigma_{1}\right)^{2}\right)}
$$

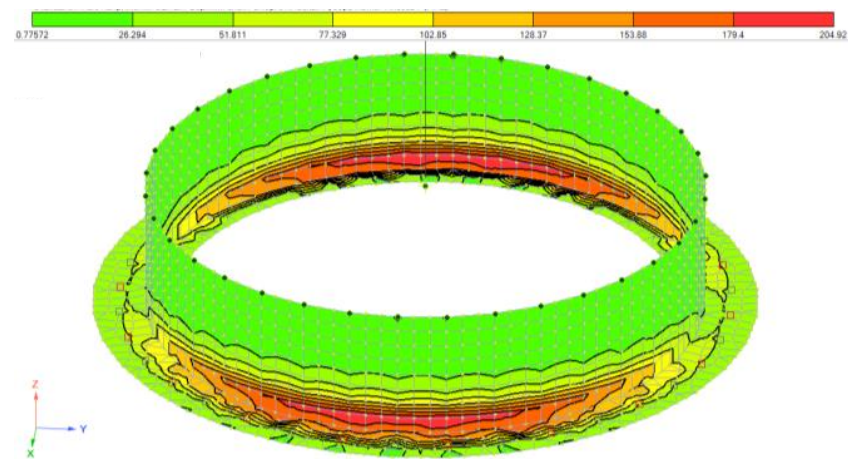

Fig. 9. Isofields of Von Mises equivalent stresses along the upper face of the support nodeplate finite elements 


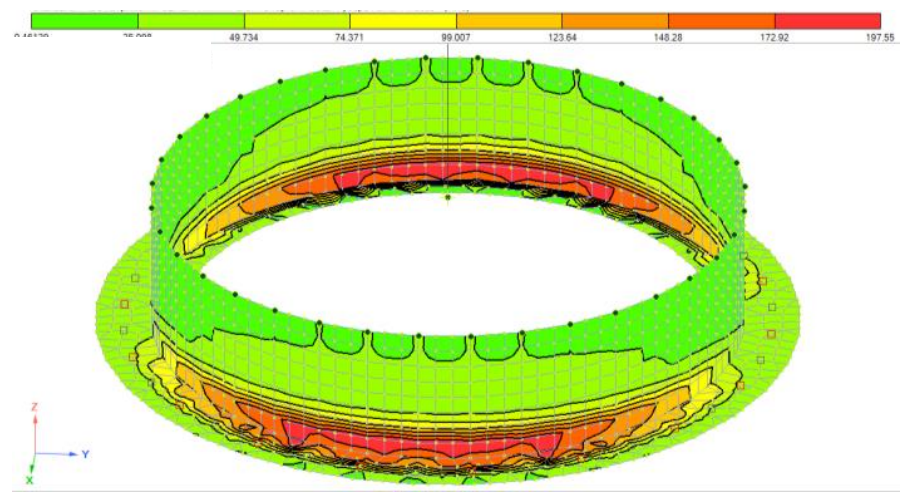

Fig. 10. Isofields of Von Mises equivalent stresses along the lower edge of the support nodeplate finite elements

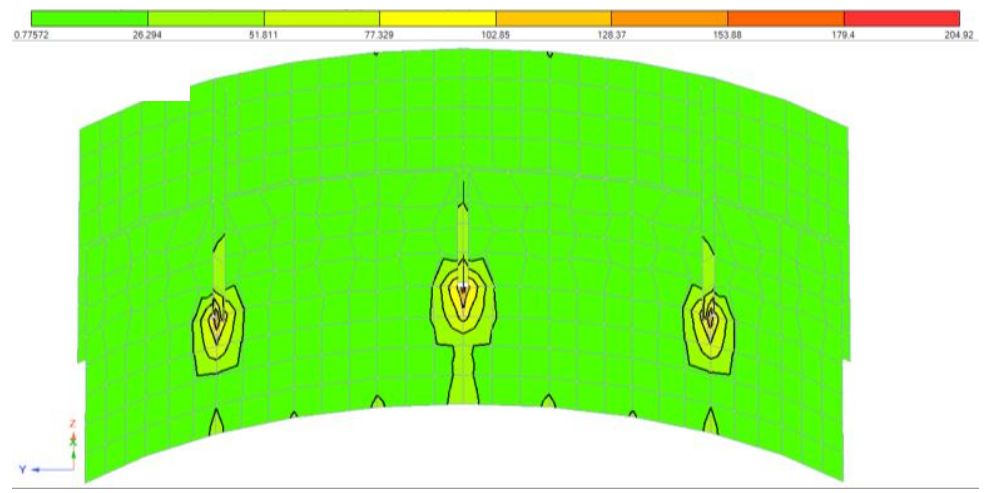

Fig. 11. Isofields of Von Mises equivalent stresses along the upper face of the telescopic jointlamellar finite elements

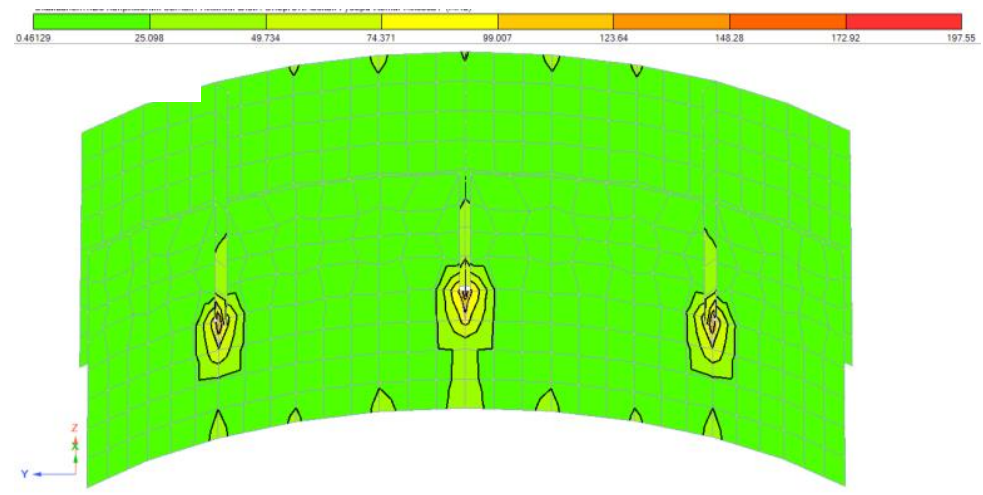

Fig. 12. Isofields of Von Mises equivalent stresses along the lower edge of the telescopic jointlamellar finite elements

\section{Summary}

1. New effective structures of tower structures, the novelty of which is confirmed by the patents of the Russian Federation, are proposed. 
2. The analysis of structural calculations applied to the WT tower Acciona AW-82-1500 class IEC IIIB showed that the use of new technical solutions can reduce material consumption by $15 \%$.

\section{References}

1. I.L. Kuznetsov, L.S. Sabitov, A.V. Isaev, Constructions with steel pipe connections of different diameters monograph of the Ministry of Education and Science of the Russian Federation, Kazan State architectural and construction university Kazan, 2012.

2. L.S. Sabitov, I.L. Kuznetsov, S.A. Penkovtsev, Privolzhsky scientific journal 4 (320), 90-94 (2014).

3. L.S. Sabitov, I.L. Kuznetsov, A.D. Ziganshin, I.K. Kiyamov, L.Sh. Akhtyamova, G.I. Kabirova, A.L. Mayilyan, S.B. Yazyev, Support from the sections of multifaceted cross-section, Patent for invention RU 2743116, applicationno. 2020128337 from 24.08.2020

4. L.S. Sabitov, I.L. Kuznetsov, A.D. Ziganshin, I.K. Kiyamov, L.Sh. Akhtyamova, G.I. Kabirova, S.R. Khairetdinov, B.M. Yazyev, Support from multifaceted sections, Patent for invention RU 2743980, applicationno. 2020128338 from 24.08.2020

5. L.S. Sabitov, I.L. Kuznetsov, A.U. Bogdanovich, Bulletin of Irkutsk State Technical University 7 (90), 71-77 (2014).

6. I.L. Kuznetsov, A.V. Isaev, L.S. Sabitov, Pipe Joint, Invention patent. RU 2288399 C8, 27.11.2006. Application no. 2005111480/06 from 07.04.2005.

7. L.S. Sabitov, I.L. Kuznetsov, I.Z. Gatiyatov, Bulletin of Civil Engineers 6 (47), 90-95 (2014).

8. L.R. Mailian, M.A. Zubritskiy, O.Yu. Ushakov, L.S. Sabitov, Calculation of altitude structures under seismic impact of the "Control earthquake" level by a nonlinear static method on the example of the adygey WPS, Building materials and products. 3(1) (2020) 14-20.

9. Yu.M. Strelkov, O.V. Radaykin, L.S. Sabitov, I.L. Kuznetsov, Structural mechanics and design of structures 1 (282) 71-79 (2019).

10.I.Z. Gatiyatov, L.S. Sabitov, I.L. Kuznetsov, Effective building structures: theory and practice collection of articles of the XIV International Scientific and Technical Conference. Editedby N.N. Laskov (2014). 